\title{
Regional stress field around the Taigu fault zone in Shanxi Province, China
}

\author{
Bin Li $\cdot$ Zihong Li $\cdot$ Mathilde B. Sørensen • Reidar Løvlie • \\ Liqiang Liu $\cdot$ Kuvvet Atakan
}

Received: 26 July 2015/ Accepted: 23 October 2015/Published online: 1 December 2015

(C) The Author(s) 2015. This article is published with open access at Springerlink.com

\begin{abstract}
A comprehensive study on regional stress field around the Taigu fault zone in Shanxi Province, China, was performed in this study. To get a better understanding of the present-day stress status in this area, 31 focal mechanisms of $M_{\mathrm{L}} \geq 3$ earthquakes since 1965 were compiled, and the best stress tensor was then inverted based on the database. Additionally, magnetic fabrics along the Taigu fault zone were investigated to get an indication of the regional stress field in the past. Our results show that the present-day stress field around the Taigu fault zone is characterized by astable NW-SE extension with a strikeslip component, consistent with the geological surveys and recent GPS data. Results from magnetic fabrics indicate that the orientations of principal stress axes from magnetic fabrics of sedimentary rocks in Neogene coincide to the orientations of principal stress axes from focal mechanisms. The south segment of the Taigu fault displays more complicated magnetic fabrics and more activity of moderate earthquakes. It is connected with the Mianshan west fault and intersects with NW-SE striking Fenyang fault and the north fault of the Lingshi uplift at the south edge of Taiyuan basin. This may be the area needing more attention in terms of seismic risk along the Taigu fault.
\end{abstract}

B. Li · Z. Li $(\square)$

Earthquake Administration of Shanxi Province, Taiyuan 030024,

China

e-mail: sxsdzjgcy@163.com

B. Li · M. B. Sørensen · R. Løvlie · K. Atakan Department of Earth Science, University of Bergen, 5007 Bergen, Norway

L. Liu

State Key Laboratory of Earthquake Dynamics, Institute of Geology, China Earthquake Administration, Beijing 100029, China
Keywords Focal mechanisms - Stress tensor inversion . Magnetic fabric - Taigu fault $\cdot$ Shanxi rift

\section{Introduction}

The Shanxi rift system, located in the east margin of the Ordos block, is composed of a series of en-echelon leftstepping asymmetrical half-graben basins (Deng et al. 1973; Xu and Ma 1992; Li et al. 2015a). The central part of the rift system is the Taiyuan basin (Fig. 1), striking NE and mainly bounded by the two major faults: the Taigu fault on the southeast and Jiaocheng fault on the northwest. Both faults are high-angle normal faults with dextral strikeslip components, and control the formation and development of the basin (Xu and Ma 1992; Zhang et al. 1998).

Compared with the Xinding basin to the north and the Linfen basin to the south, no $M_{\mathrm{S}} \geq 7.0$ earthquakes were recorded in the Taiyuan basin. This makes many people conclude that this basin has no strong-earthquake development conditions (Xie et al. 2004; Guang and Sun 1993; Yang 1996). However, recent studies on paleo-earthquakes by digging trenches on the Jiaocheng fault reveal that at least $3 M_{\mathrm{S}} \geq 7.0$ earthquakes have occurred in the last 10,000 years in this basin (Zhao et al. 2005; Xie et al. 2008). By using the network seismic data in 1970-2003, Yi et al. (2004) estimated the long-term seismic potential along the Taiyuan-Linfen portion of the Shanxi rift system based on the computing mean seismic-moment rates and the mapping of $b$-values. Their results show that in the Jiexiu-fenyang segment of the Taiyuan basin the accumulated stress is relatively high (Fig. 1), and this area was identified as one of the two potential risky areas for the coming earthquakes in the Shanxi rift system. Additionally, studies on Coulomb stress transfer also show that the 


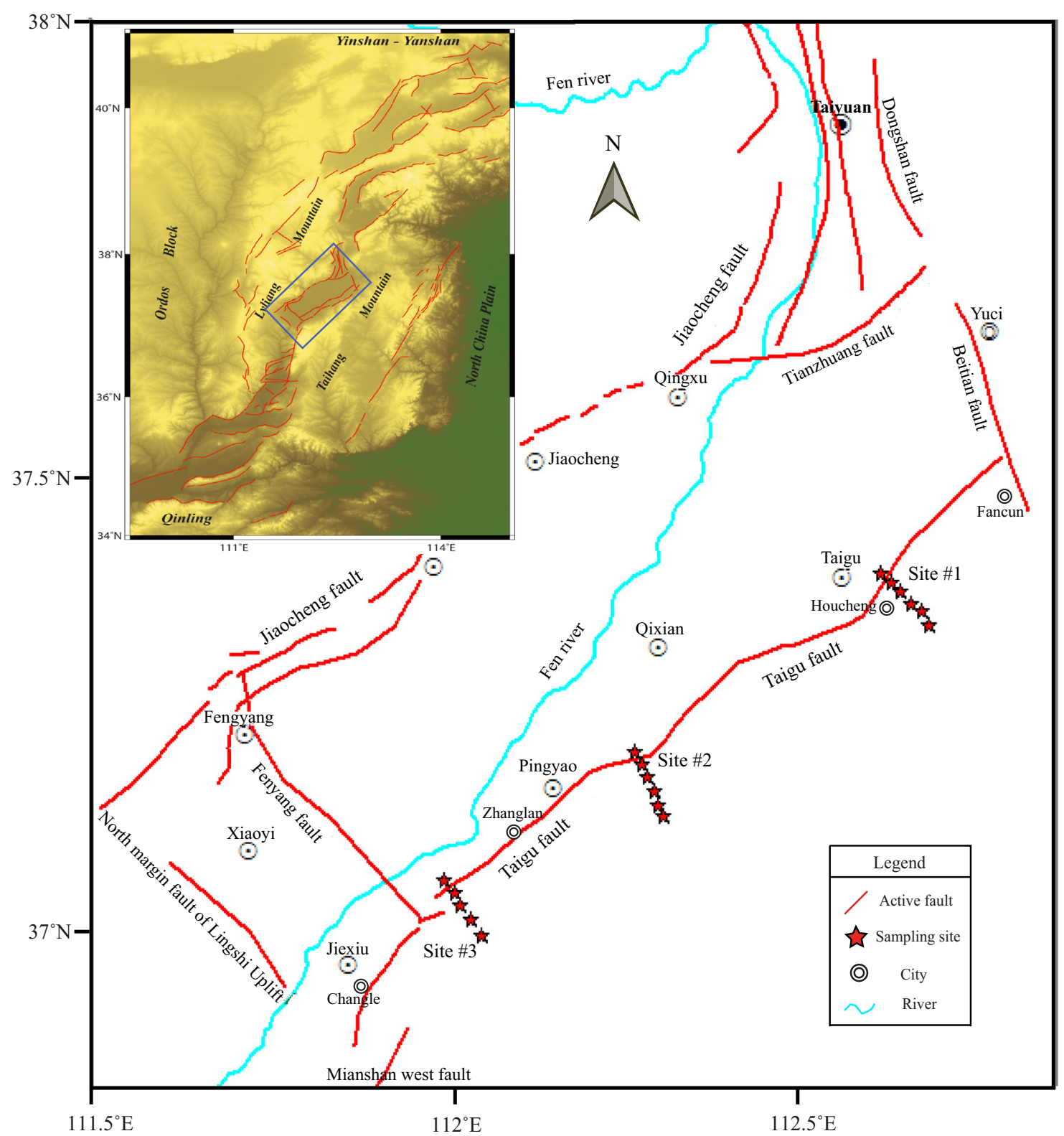

Fig. 1 Regional tectonics of the area around the Taiyuan basin, and sampling sites for magnetic fabric study (red stars)

Coulomb stress in the Taiyuan basin has increased significantly in the past 700 years, indicating a high seismic risk of this area, too (Shen et al. 2004; Liu et al. 2007).

As one of the two major seismogenic faults in the Taiyuan basin, little work has been done for the Taigu fault compared with the Jiaocheng fault to the northwest side. The first concrete study on the Taigu fault was reported by Deng et al. (1973) that reveal the fault is a normal fault, cutting through the lower Pleistocene strata in Quaternary. Studies by Xu (1989) indicate that the Taigu fault extends southward in connection with the Huoshan piedmont fault to the south, and conclude that the Taigu fault has the dextral strike-slip component. Based on the borehole data
Wang and Yang (1996) found that the faulting displacement since Quaternary is up to $100 \mathrm{~m}$, with a vertical movement rate of $0.1 \mathrm{~mm} / \mathrm{a}$. Later, Xie et al. (2004) investigated the Holocene activities along the Taigu fault zone. They found some evidences indicating that the Taigu fault is active in the Holocene, and concluded that the 1303 Hongdong $M_{\mathrm{S}} 8.0$ earthquake ruptured through the Mianshan west fault and also caused the movement of the Taigu fault. This is still controversial because some other studies show that the rupture zone of the 1303 Hongdong $M_{\mathrm{S}} 8.0$ earthquake is limited within the Huoshan piedmont fault to the south of our study area (Xu and Deng 1990; Xu and Ma 1992; Zhang et al. 1998). 
However, these studies were mainly focused on the field investigation on fracture zone distribution, neotectonic activities and the relationship of the Taigu fault with the 1303 Hongdong $M_{\mathrm{S}} 8.0$ earthquake. On the other hand, the development of strong earthquakes is also controlled by the regional stress field influencing the seismogenic faults. The Taigu fault is located at the extensional line of the Huoshan fault, which generated the 1303 Hongdong $M_{\mathrm{S}} 8.0$ earthquake with the rupture direction towards the Taigu fault. Therefore, further studies on local stress field and potential seismic risk arevery are necessary for this fault zone. In this study, we use multiple methods to study the local stress field around the Taigu fault zone comprehensively, which include analyzing the recently obtained new focal mechanisms of $M_{\mathrm{L}} \geq 3.0$ earthquakes and stress tensor inversion based on the focal mechanisms database (Li et al. 2015b) to get better understanding of the present stress field status, and investigating rock magnetic fabrics along the Taigu fault zone to rich the information of the stress field in the past. All these results will contribute to a better understanding of the potential seismicity and seismic hazard of the fault zone.

\section{Geological setting}

The Taigu fault is around $100 \mathrm{~km}$ long in total, with a general strike of $\mathrm{N} 45^{\circ} \mathrm{E}$. It starts from the Fancun of Taigu County in the north, extending southward to Changle in Jiexiu area via Hongcheng and Zhanglan in the middle (Fig. 1). Unlike the Jiaocheng fault, the bedrock boundary between the mountain and basin along the Taigu fault is not very clear. In its north segment the fault lies between the piedmont of bedrocks and the alluvial fan edge of the basin, and in the south segment it is located between the alluvial fan edge and loess terraces (Xie et al. 2004). Exposed bedrock around the Taigu fault includes Cambrian-Ordovician carbonate rocks and Triassic clastic and sand rocks. The thickness of Cenozoic sediments ranges between $50 \mathrm{~m}$ and $3800 \mathrm{~m}$. Along the fault, some gullies in different places are found to be offset rightward, indicating the existing of dextral strikeslip movement of the fault. Trenches were dig along the Taigu fault, showing the evidence for Holecene activities of the fault (Xie et al. 2004). In recent years, ground fissures have developed fast and several large ground fissures with several hundred to several thousand meters long were found. Seismicity was also very active for the area around the Taigu fault zone. Since the first earthquake recorded in 712 (Pingyao $M_{\mathrm{S}} 5.5$ ), five $M_{\mathrm{S}} \geq 5.0$ earthquakes occurred in the area around the Taigu fault zone. The largest instrumental earthquake is the 1979 Jiexiu earthquake with a magnitude of $M_{\mathrm{S}}$ 5.1.

\section{Focal mechanisms and inversion of the present stress state}

\subsection{Focal mechanism data}

The focal mechanism data used in this study were taken from Li et al. (2015b). In their study focal mechanisms of earthquakes $M_{\mathrm{L}} \geq 3.0$ with the time period from Jan. 2008 to Apr. 2014 were newly determined based on the recordings from the Shanxi Seismic Network (SSN), and previous solutions were also collected and complied from variable published sources.

Two widely used programs, FOCMEC (Snoke et al. 1984; Snoke 2003) and FPFIT (Reasenberg and Oppenheimer 1985), were applied for determination of focal mechanisms in the study of Li et al. (2015b). Both methods assume a pure double-couple mechanism, and perform a grid search for the acceptable solutions based on the P-wave first motion polarities. For events with $M_{\mathrm{L}} \geq 3.6$ with clear signals and high signal-to-noise ratios, moment tensor inversion of full waveforms were performed by using the time-domain moment tensor inversion method (TDMT_INV code) (Dreger 2002). For a detailed description about the data processing, and solutions determination and evaluation, please refer to $\mathrm{Li}$ et al. (2015b).

A total of 31 focal mechanisms are available and they are plotted in Fig. 2. Most solutions show either normal or strike-slip faulting mechanisms, and a few inverted solutions are found around the north and south end of the Taiyuan basin. The detailed source parameters of them are given in Table 1.

\subsection{Inversion of the present stress field}

In order to further understand the present stress state of the Taigu fault zone, stress tensor inversion was performed based on the focal mechanism database for the area around the Taiyuan basin. Two different methods, the SLICK (Michael 1984, 1987) and the TENSOR (Delvaux and Sperner 2003), are used. Both have been widely used and generally have a good performance for determination of stress parameters (Hardebeck and Hauksson 2001; Gorgun et al. 2010; Delvaux and Barth 2010). The SLICK algorithm inverts both nodal planes as if they were independent data and chooses the better one while determining the best stress tensor by using the improved Gephart and Forsyth's grid search algorithm (Gephart and Forsyth 1984). While the TENSOR method applies an interactive processing of choosing correct nodal planes which gives the smaller misfits (Delvaux and Barth 2010).

The detailed results of the stress tensor inversion are displayed in Fig. 3. The orientations of the principal 


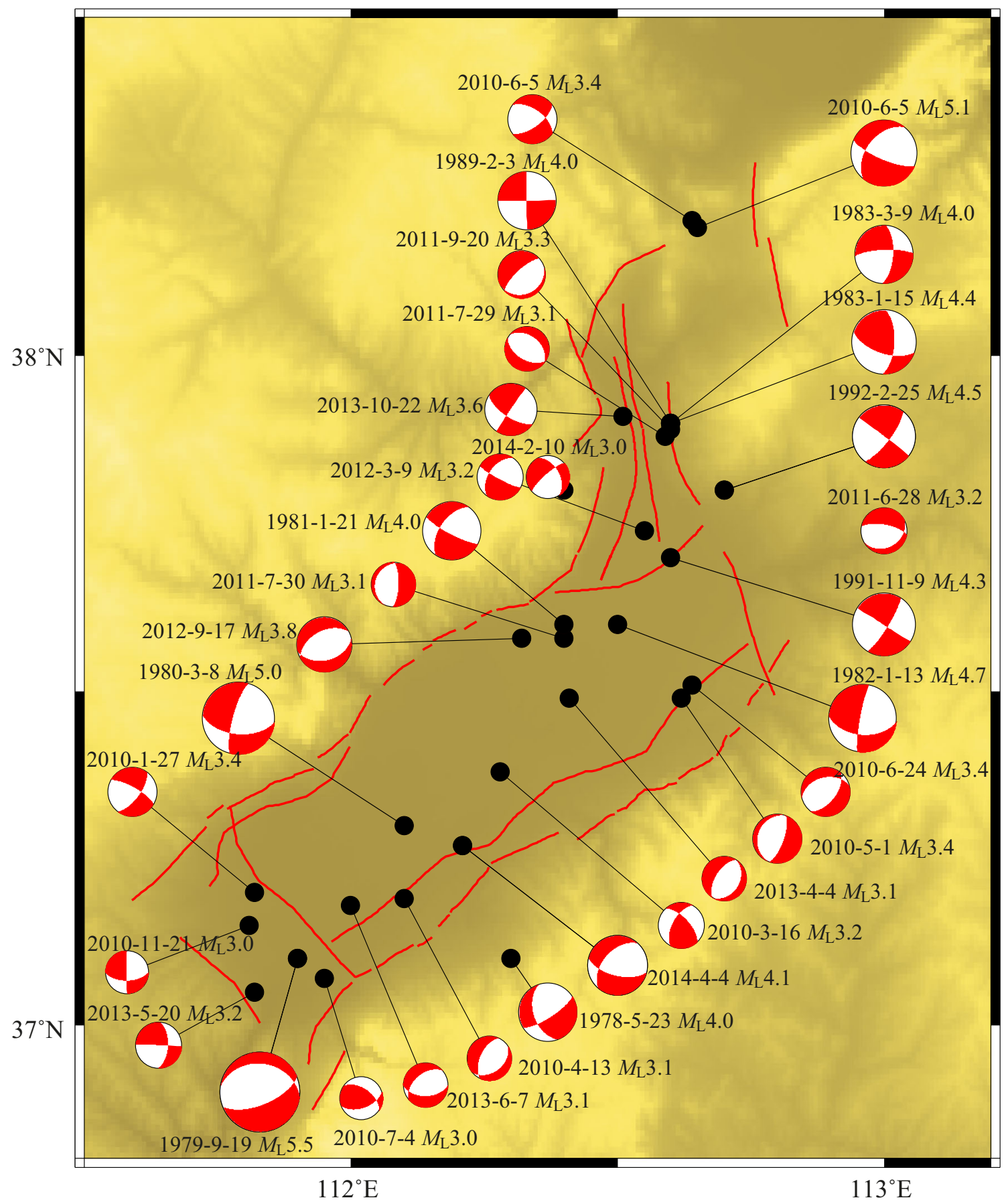

Fig. 2 Spatial distribution of 30 focal mechanisms; see Table 1 for detailed parameters of each solution

stresses $\sigma_{1}, \sigma_{2}$ and $\sigma_{3}$ (maximum, intermediate and minimum principal compressive stress, with $\sigma_{1}>\sigma_{2}>\sigma_{3}$ ) from both SLICK and TENSOR methods give comparable results. $\sigma_{1}$ strikes ENE with a plunge of $45^{\circ}-65^{\circ}, \sigma_{2}$ strikes SSW with a plunge of $23^{\circ}-45^{\circ}$ and $\sigma_{3}$ is sub-horizontal with a strike of WNW. Both methods give normal faulting with strike-slip component stress regime for the area. Orientation variations of $\sigma_{1}$ and $\sigma_{2}$ can be observed along their strikes, while $\sigma_{3}$ is very stable and consistent for both methods. All these results indicate that the regional stress field is dominated by the NNW-SSE extension. The misfit of the stress tensor inversion is generally quantified by the parameter $\beta$, which is the angle between the resolved slip vector from stress tensor inversion and the observed slip vector from fault plane solutions (Michael 1987; Gorgun et al. 2010). For all cases, the mean $\beta$ value $(\bar{\beta})$, which is a 
Table 1 Source parameters of 31 events in the Taiyuan basin (projected in the lower hemisphere) (Li et al. 2015b)

\begin{tabular}{|c|c|c|c|c|c|c|c|c|c|}
\hline \multirow[t]{2}{*}{ ID } & \multirow{2}{*}{$\begin{array}{l}\text { Date } \\
\text { (y-mo-d) }\end{array}$} & \multirow{2}{*}{$\begin{array}{l}\text { Time } \\
\text { h:mim:s }\end{array}$} & \multicolumn{3}{|l|}{ Location } & \multirow{2}{*}{$\begin{array}{l}\text { Mag. } \\
M_{\mathrm{L}}\end{array}$} & \multicolumn{3}{|c|}{ Frist nodal plane } \\
\hline & & & Lat. $\left({ }^{\circ} \mathrm{N}\right)$ & Long. $\left({ }^{\circ} \mathrm{E}\right)$ & Depth $(\mathrm{km})$ & & Strike & Dip & Rake \\
\hline 8 & $1978-05-23$ & $18: 11: 15.0$ & 37.1 & 112.3 & 25 & 4.0 & 57 & 75 & -44 \\
\hline 11 & 1979-06-19 & $04: 15: 19.2$ & 37.1 & 111.9 & 33 & 5.5 & 278 & 30 & -63 \\
\hline 13 & 1980-03-08 & $21: 54: 14.7$ & 37.3 & 112.1 & 22 & 5.0 & 195 & 76 & -143 \\
\hline 14 & 1981-01-21 & $18: 20: 02.0$ & 37.6 & 112.4 & 24 & 4.0 & 215 & 55 & -167 \\
\hline 15 & $1982-01-13$ & $15: 17: 45.9$ & 37.6 & 112.5 & 27 & 4.7 & 190 & 83 & -140 \\
\hline 19 & $1983-01-15$ & $17: 38: 35.6$ & 37.9 & 112.6 & 19 & 4.4 & 3 & 64 & 148 \\
\hline 20 & 1983-03-09 & 11:28:02.0 & 37.9 & 112.6 & 12 & 4.0 & 4 & 65 & -165 \\
\hline 23 & 1989-02-03 & $14: 37: 20.1$ & 37.9 & 112.6 & 18 & 4.0 & 179 & 88 & -179 \\
\hline 31 & 1991-11-09 & $05: 14: 57.2$ & 37.7 & 112.6 & 14 & 4.3 & 32 & 80 & 179 \\
\hline 32 & $1992-02-25$ & $17: 17: 53.0$ & 37.8 & 112.7 & 12 & 4.3 & 37.5 & 75 & -179 \\
\hline 52 & 2010-01-27 & $04: 28: 53.5$ & 37.204 & 111.421 & 7.9 & 3.4 & 299 & 73 & -25 \\
\hline 55 & 2010-03-16 & $12: 44: 53.2$ & 37.278 & 112.175 & 8.0 & 3.2 & 317 & 63 & 36 \\
\hline 61 & 2010-04-13 & $02: 15: 25.9$ & 37.103 & 112.067 & 8.5 & 3.1 & 53 & 38 & -66 \\
\hline 62 & 2010-05-01 & $16: 07: 42.0$ & 37.286 & 112.320 & 17.9 & 3.4 & 19 & 70 & -90 \\
\hline 64 & 2010-06-05 & $12: 58: 11.2$ & 38.187 & 112.651 & 7.1 & 5.1 & 113 & 74 & -45 \\
\hline 65 & 2010-06-05 & $15: 00: 03.6$ & 38.126 & 112.439 & 4.2 & 3.4 & 54 & 64 & -141 \\
\hline 67 & 2010-06-24 & $01: 13: 22.6$ & 37.313 & 112.439 & 12.4 & 3.4 & 38 & 56 & -112 \\
\hline 68 & 2010-07-04 & $16: 16: 28.8$ & 37.066 & 111.546 & 8.9 & 3.0 & 70 & 54 & 49 \\
\hline 70 & 2010-07-30 & $10: 02: 45.2$ & 37.379 & 112.201 & 8.4 & 3.1 & 1 & 72 & -97 \\
\hline 77 & 2010-11-21 & $12: 27: 11.5$ & 37.145 & 111.608 & 9.0 & 3.0 & 179 & 89 & -148 \\
\hline 90 & 2011-06-28 & $02: 45: 06.0$ & 37.499 & 112.583 & 10.9 & 3.2 & 60 & 28 & -126 \\
\hline 92 & 2011-07-29 & $15: 28: 30.9$ & 37.578 & 112.390 & 12.5 & 3.1 & 120 & 50 & -96 \\
\hline 95 & 2011-09-20 & 04:29:05.4 & 37.592 & 112.398 & 16.5 & 3.3 & 66 & 19 & -70 \\
\hline 103 & 2012-03-09 & 132030.4 & 37.436 & 112.353 & 10.1 & 3.2 & 118 & 82 & -41 \\
\hline 110 & 2012-09-17 & $02: 43: 42.7$ & 37.575 & 112.325 & 14.1 & 3.8 & 77 & 43 & -77 \\
\hline 112 & 2012-10-05 & 002540.8 & 36.309 & 111.430 & 22.1 & 3.2 & 6 & 74 & 140 \\
\hline 122 & 2013-04-04 & 11:01:54.9 & 37.488 & 112.430 & 16.7 & 3.1 & 212 & 58 & -89 \\
\hline 123 & 2013-05-20 & $11: 40: 13.9$ & 37.054 & 111.822 & 10.0 & 3.2 & 3 & 58 & -179 \\
\hline 129 & 2013-06-27 & $17: 11: 26.8$ & 37.184 & 112.005 & 8.2 & 3.1 & 89 & 50 & -61 \\
\hline 134 & 2013-10-22 & 11:08:6.1 & 37.909 & 112.510 & 26.9 & 3.6 & 123 & 66 & -1 \\
\hline 139 & 2014-02-10 & $12: 10: 40$ & 37.800 & 112.405 & 20.6 & 3.0 & 229 & 77 & -44 \\
\hline 143 & 2014-04-04 & $15: 16: 39.4$ & 37.271 & 112.209 & 13.4 & 4.1 & 103 & 62 & -47 \\
\hline \multirow[t]{2}{*}{ ID } & \multicolumn{3}{|c|}{ Second nodal plane } & \multicolumn{2}{|l|}{$P$ axis } & \multicolumn{2}{|l|}{$T$ axis } & \multirow{2}{*}{\multicolumn{2}{|c|}{ Source }} \\
\hline & Strike & Dip & Rake & $\mathrm{Az}$ & $\mathrm{Pl}$ & $\mathrm{Az}$ & $\mathrm{Pl}$ & & \\
\hline 8 & 161 & 48 & -160 & 9 & 41 & 115 & 17 & Liu & (1993) \\
\hline 11 & 68 & 63 & -105 & 309 & 68 & 169 & 17 & Har & CMT \\
\hline 13 & 94 & 54 & -18 & 61 & 36 & 320 & 14 & Liu & (1993) \\
\hline 14 & 118 & 80 & -36 & 70 & 32 & 172 & 16 & Liu & (1993) \\
\hline 15 & 94 & 49 & -9 & 60 & 33 & 316 & 22 & Liu & (1993) \\
\hline 19 & 108 & 62 & 30 & 56 & 1.5 & 325 & 40 & Liu & (1993) \\
\hline 20 & 267 & 76 & -26 & 224 & 28 & 317 & 8 & Liu & (1993) \\
\hline 23 & 89 & 89 & -2 & 44 & 2 & 134 & 1 & Liu & (1993) \\
\hline 31 & 122 & 89 & 10 & 256 & 6 & 348 & 8 & Liu & (1993) \\
\hline 32 & 307 & 89 & -15 & 262 & 11 & 353 & 10 & Liu & (1993) \\
\hline 52 & 37 & 66 & -161 & 257 & 30 & 349 & 4 & $\mathrm{Li} \mathrm{e}$ & (2015b) \\
\hline 55 & 209 & 58 & 148 & 82 & 3 & 175 & 44 & Li e & (2015b) \\
\hline
\end{tabular}


Table 1 continued

\begin{tabular}{|c|c|c|c|c|c|c|c|c|}
\hline \multirow[t]{2}{*}{ ID } & \multicolumn{3}{|c|}{ Second nodal plane } & \multicolumn{2}{|c|}{$P$ axis } & \multicolumn{2}{|c|}{$T$ axis } & \multirow[t]{2}{*}{ Source } \\
\hline & Strike & Dip & Rake & $\mathrm{Az}$ & $\mathrm{Pl}$ & $\mathrm{Az}$ & $\mathrm{Pl}$ & \\
\hline 61 & 204 & 56 & -108 & 67 & 73 & 306 & 9 & Li et al. (2015b) \\
\hline 62 & 200 & 20 & -89 & 288 & 65 & 109 & 25 & Li et al. (2015b) \\
\hline 64 & 218 & 47 & -158 & 66 & 42 & 172 & 17 & Li et al. (2015b) \\
\hline 65 & 304 & 56 & -32 & 273 & 45 & 177 & 5 & Li et al. (2015b) \\
\hline 67 & 254 & 40 & -61 & 258 & 70 & 144 & 9 & Li et al. (2015b) \\
\hline 68 & 305 & 52 & 132 & 188 & 1 & 279 & 58 & Li et al. (2015b) \\
\hline 70 & 202 & 19 & -70 & 261 & 62 & 96 & 27 & Li et al. (2015b) \\
\hline 77 & 89 & 58 & -1 & 49 & 23 & 310 & 21 & Li et al. (2015b) \\
\hline 90 & 279 & 68 & -73 & 217 & 63 & 356 & 21 & Li et al. (2015b) \\
\hline 92 & 309 & 40 & -83 & 353 & 83 & 214 & 5 & Li et al. (2015b) \\
\hline 95 & 245 & 72 & -97 & 125 & 62 & 320 & 27 & Li et al. (2015b) \\
\hline 103 & 214 & 50 & -169 & 68 & 34 & 173 & 21 & Li et al. (2015b) \\
\hline 110 & 240 & 48 & -102 & 85 & 81 & 338 & 3 & Li et al. (2015b) \\
\hline 112 & 109 & 52 & 20 & 62 & 14 & 321 & 39 & Li et al. (2015b) \\
\hline 122 & 30 & 32 & -92 & 125 & 77 & 301 & 13 & Li et al. (2015b) \\
\hline 123 & 272 & 89 & -32 & 223 & 23 & 322 & 21 & Li et al. (2015b) \\
\hline 129 & 228 & 48 & -120 & 66 & 68 & 159 & 1 & Li et al. (2015b) \\
\hline 134 & 213 & 89 & -156 & 81 & 17 & 346 & 16 & Li et al. (2015b) \\
\hline 139 & 331 & 47 & -162 & 180 & 40 & 286 & 19 & Li et al. (2015b) \\
\hline 143 & 220 & 50 & -142 & 65 & 52 & 164 & 7 & Li et al. (2015b) \\
\hline
\end{tabular}

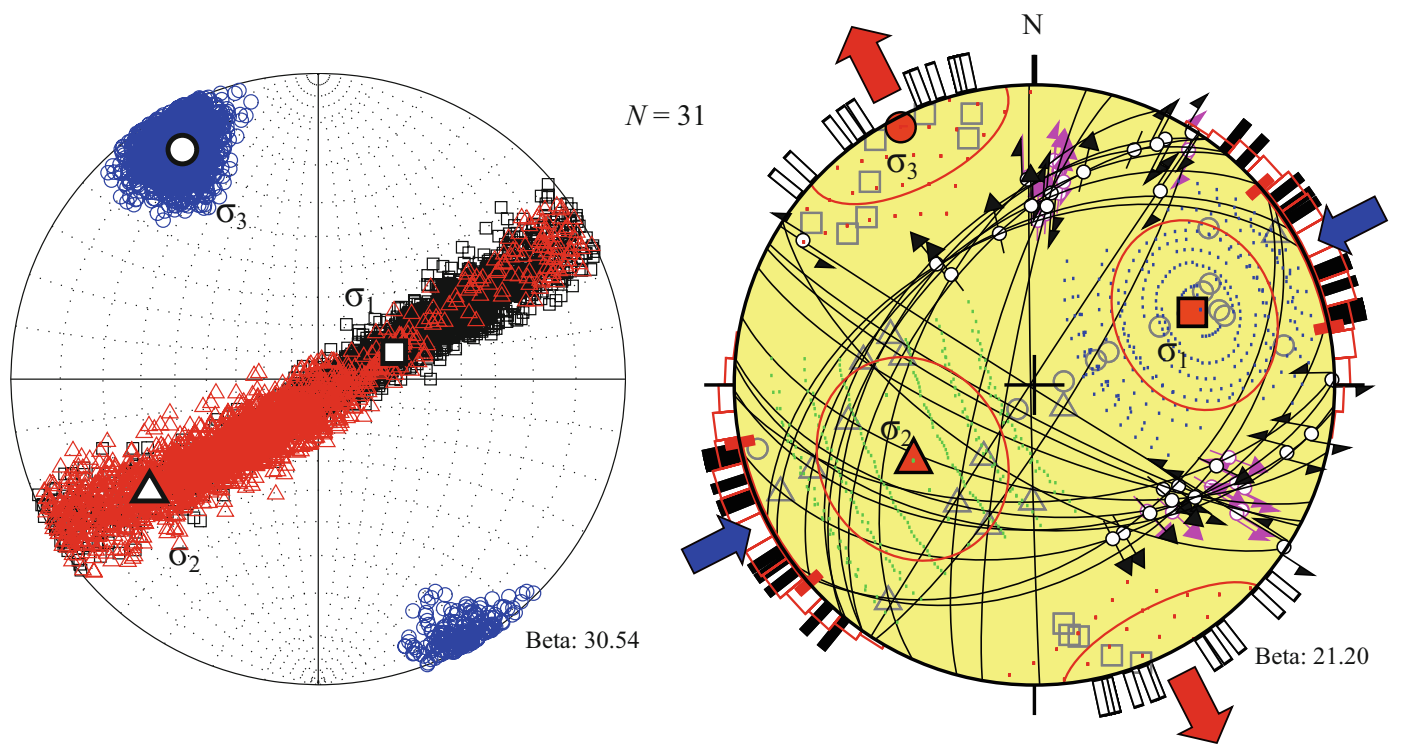

Fig. 3 Results of stress tensor inversion from 31 focal mechanism solutions $(N=31)$ for the Taiyuan basin based on both SLICK $(l e f t)$ and TENSOR (right) methods. Left: black squares represent the $95 \%$ confidence region for maximum principal stress $\left(\sigma_{1}\right)$; red triangles represent the $95 \%$ confidence region for intermediate principal stress $\left(\sigma_{2}\right)$; blue circles represent the $95 \%$ confidence region for minimum principal stress $\left(\sigma_{3}\right)$. Right: big red circles indicate the $95 \%$ confidence region for $\sigma_{1}, \sigma_{2}$ and $\sigma_{3}$; black and pink lines with small arrows show the faulting plane and direction of each solution; small bars outside the stereogram represent the maximum horizontal stress $\left(S_{\mathrm{Hmax}}\right.$; black) and the minimum horizontal stress $\left(S_{\mathrm{Hmax}}\right.$; white) directions of individual focal mechanisms; the small grey symbols inside show the orientations of the related kinematic axes (circle: $P$ axis, triangle: $B$ axis, square: $T$ axis); red, blue and green dots around each principle stress axis are results from each iterative procedure; big blue and red arrows outside the large circle indicate compressional and extensional directions, respectively 
mean of all $\beta$-values, decreases with increasing in homogeneity of stress field and $\bar{\beta} \leq 33^{\circ}$ is generally interpret a homogeneous state of stress field (Gorgun et al. 2010). The $\bar{\beta}$ value from the SLICK in this study is found to be $30^{\circ}$, indicating a homogenous stress regime of this area.

\section{Magnetic fabrics of rock samples along Taigu fault}

\subsection{Method}

Most rocks in nature contain magnetic minerals, which make them exhibit some magnetic properties, e.g., the magnetic susceptibility $(K)$, which is the ratio of the induced magnetization $(M)$ to the inducing magnetic field strength $(H)$. However, the magnetic susceptibility in most rocks is anisotropic, caused by a combination of the preferred orientation of grains, mineral grain distribution or their lattice-preferred orientation, and the intrinsic anisotropy of the grains (shape or crystalline anisotropy) (Tarling and Hrouda 1993; Ferré et al. 2014).

The anisotropy of magnetic susceptibility (AMS) technique is turned out to be a well-established petrofabric tool for indicating relative strain and the rock deformation pattern related to various tectonic settings (Kissel et al. 1986; Borradaile and Alford 1988; Rochette et al. 1992; Tarling and Hrouda 1993; Parés and van der Pluijm 2002; Ferré et al. 2014). Since Graham (1954) initially proposed this method, it has been widely used to constrain strain in many studies (Tarling and Hrouda 1993; Parésand van der Pluijm 2002; Gébelin et al. 2006; Mamtani et al. 2011; Gentoso et al. 2012; Fleming et al. 2013). Numerous studies based on mathematic modeling (e.g., Owens and Rutter 1978; Hrouda 1993), laboratory experiments (e.g., Borradaile and Alford 1987, 1988; Till et al. 2010) and field rock deformation surveys (e.g., Kissel et al. 1986; Parés et al. 1999) indicate that the AMS can be idealized as a symmetric second rank tensor and represented as an ellipsoid with three perpendicular principal axes, $K_{1}, K_{2}$, and $K_{3}$ (maximum, intermediate and minimum principal axes, with $K_{1}>K_{2}>K_{3}$ ). Moreover, the principal AMS axes, $K_{1}, K_{2}$, and $K_{3}$ coincide with the finite strain axes, $X$, $Y$, and $Z$, respectively (Borradaile and Tarling 1981; Rathore 1979; Borradaile 1991; Tarling and Hrouda 1993).

Several parameters have been defined for quantification of the magnitude of anisotropy and the shape of ellipsoid. For instance, the corrected anisotropy degree, $P_{j}$, is a measurement of the degree to which the AMS ellipsoid deviates from a sphere (Jelinek 1981), calculated by

$P_{j}=\exp \sqrt{2 \sum\left(\ln K_{i}-\ln K_{\mathrm{m}}\right)^{2}}$, where $i=1$ to 3 , and $K_{\mathrm{m}}$ is the arithmetic mean susceptibility with $K_{\mathrm{m}}=\left(K_{1}+K_{2}+K_{3}\right) / 3 . P_{j}$ is equal to 1 for rocks without preferred orientation of minerals. Additionally, $T$ is the shape parameter used to describe the shape of the AMS ellipsoid, calculated by

$T=\frac{\left(2 \ln K_{2}-\ln K_{1}-\ln K_{3}\right)}{\left(\ln K_{1}-\ln K_{3}\right)}$.

$T$-value varies between -1 and $+1 ; 0 \leq T \leq 1$ indicates an oblate shape of AMS ellipsoid, and a prolate AMS ellipsoid with $-1 \leq T \leq 0$. These AMS parameters are used in the following to describe the magnetic fabrics of rock samples along the Taigu fault zone.

\subsection{Sampling and measurement}

Three sites along the Taigu fault were selected for sampling in this study: Site \#1 $\left(37.445^{\circ} \mathrm{N}, 112.653^{\circ} \mathrm{E}\right)$ in the north, Site \#2 $\left(37.21^{\circ} 2 \mathrm{~N}, 112.317^{\circ} \mathrm{E}\right)$ in the middle and Site \#3 $\left(37.058^{\circ} \mathrm{N}, 112.011^{\circ} \mathrm{E}\right)$ in the south segments, as shown in Fig. 1. Samples were collected along a profile crossing the Taigu fault at each site. Sandstone and mudstone samples in Neogene were drilled with a petrolpowered portable drill in the field. For each sampling position at least two samples were obtained, and all the samples were oriented by the magnetic compass in the field. Totally, 212 samples were obtained through three field campaigns in 2010 and 2011.

In the laboratory, samples were trimmed into $2.2 \mathrm{~cm}$ long cylinders with a diameter of $2.54 \mathrm{~cm}$. Sample trimming procedure includes the drawing of orientation lines, cutting the drilled cylinders and grinding their end and top surface. All these oriented samples were measured at the Paleomagnetism and Geochronology Laboratory (SKLLE), Institute of Geology and Geophysics, Chinese Academy of Sciences, with a KLY-3s Kappa bridge (AGICO).

\subsection{Results}

\subsubsection{Magnetic fabric parameters}

The mean magnetic susceptibility $\left(K_{\mathrm{m}}\right)$ varies from $86 \times 10^{-6}$ to $128 \times 10^{-6} \mathrm{SI}$ for samples in this study. It is low and typical of sedimentary rocks with low ferromagnetic content. Figure 4 shows diagrams of corrected degree of anisotropy $\left(P_{j}\right)$ versus the shape parameter $(T)$ for both all samples and individual datasets of each site. The $P_{j}$ values are all less than 1.10 , indicating typically weakly deformed sedimentary rocks. Compared the $P_{j}$ values between the three sites, more data with higher $P_{j}$ values are observed at the Site \#3. The shape parameter $T$ provides a quantitative measure of the AMS ellipsoid shape. As 


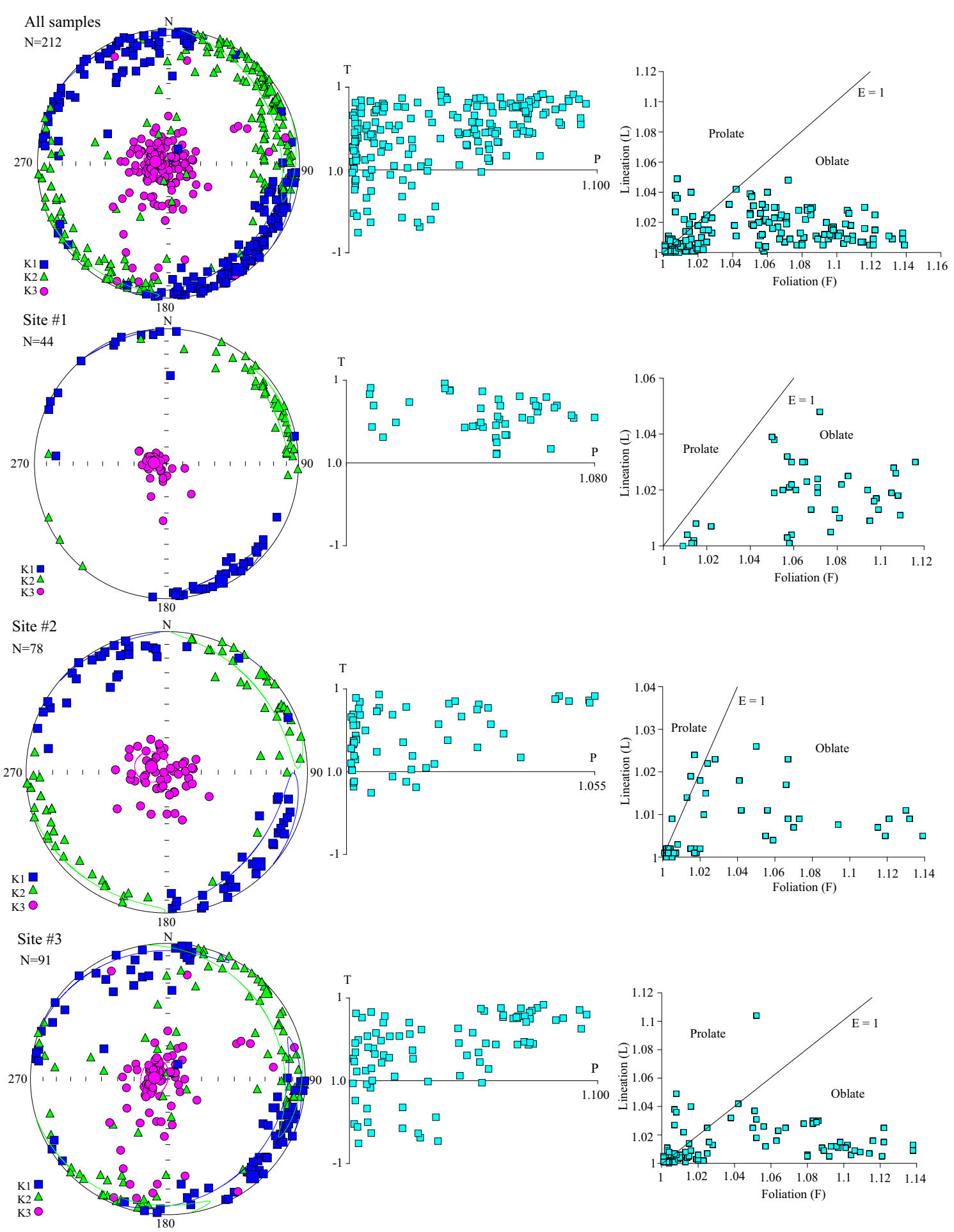

Fig. 4 Results of magnetic fabrics of the three selected sites along the Taiguan fault zone (Fig. 1). The first diagrams on the left show the equalarea stereograms in the lower hemisphere of magnetic fabrics after rock bedding correction:squares are maximum susceptibility $\left(K_{1}\right)$; triangles are intermediate susceptibility $\left(K_{2}\right)$; and circles are minimum susceptibility $\left(K_{3}\right)$; dashed line ellipses are $95 \%$ confidence ellipses. The middle column shows the $P_{j}-T$ diagrams and the right is the Flinn diagrams 
shown in Fig. 4, most data give $T \geq 0$, indicating a distribution within the oblate fieldfor most samples (Jelinek 1981). Parés (2004) proposed a general development path of anisotropy parameters with increasing in deformation intensity. The data from the Taigu fault zone in the $P_{j}-T$ diagram seems to exhibit this kind of feature, $T$-values increasing as the increasing of the corrected degree of anisotropy.

The shape of the magnetic fabrics can also be illustrated by the Flinn diagram, in which $X$ - and $Y$-axes represent the foliation $\left(F=K_{2} / K_{3}\right)$ and the lineation $\left(L=K_{1} / K_{2}\right)$ of magnetic fabrics, respectively. The whole diagram area is divided into two by the line $E=1$, representing two types of different ellipsoid shapes (oblate and prolate). The data within the $E>1$ area indicate that they have a prolate type of magnetic fabrics, while the data within the $E<1$ area mean a oblate type of magnetic fabrics. Figure 4 shows the data distribution for the area in the Flinn diagram. It is observed that most data fall into the oblate area, consistent with the interpretation of magnetic fabric shape in terms of the $P_{j}$ versus $T$ diagram.

\subsubsection{Magnetic fabric orientation}

The orientation of magnetic fabrics is generally illustrated by stereograms. That is projecting the AMS principal axes, $K_{1}, K_{2}$ and $K_{3}$, on an equal-area hemisphere (lower). Figure 4 shows the stereograms after bedding correction for all of the samples and individual dataset from each of the three sites along the Taigu fault zone. All of the axes of the AMS ellipsoid are well grouped. $K_{1}$ distributes around the edge of the stereogram with a nearly horizontal orientation, and has a preferred distribution along the NW-SE direction. Similar distribution of $K_{2}$ axis with the $K_{1}$ is observed, concentrating around the edge of the stereogram, but its preferred distribution is perpendicular to that of $K_{1}$ axis. The minimum axis $\left(K_{3}\right)$ shows a subvertical orientation and distributes around the center of the stereogram.

The magnetic fabric orientation of individual datasets of the three sites seems similar with the total dataset. The main difference between them is that the $K_{3}$-axis from Site \#3 seems more complicated, with a preferred distribution along the NNE-SSW orientation. This may be related to the special location of Site \#3 and the reason for this difference will be discussed in the following section.

\section{Discussion}

The stress tensor inversion from focal mechanism solutions in the Taiyuan basin gives a clear conclusion that the regional stress field is mainly characterized by the NNWSSE extension regime, dominated by normal faulting with strike-slip component. This is generally consistent with the understanding from geological field surveys as mentioned in introduction. Frequent occurrence of moderate to small earthquakes along the Taigu fault zone might indicate the activities of the fault. The feature of the regional stress field inferred from the stress tensor inversion is also consistent with GPS data, which has been used for monitoring the crustal deformation/movement of the region since 1992 (He et al. 2003). As indicated by the recent study by $\mathrm{Qu}$ et al. (2014) based on a near 10-year GPS data, the Taiyuan basin is now still extending with an extensional rate of $\sim 2.8 \mathrm{~mm} /$ yralong the near NW-SE direction. The comparison of the stress field with previous studies, e.g., $\mathrm{Xu}$ et al. (1992), (2008) and Wan (2010), shows that it generally agrees to the stress field in a large scale, indicating that in the area around the Taigu fault the local stress field is still mainly controlled by the stress field in a large scale.

From the focal mechanism data and stress tensor inversion, it is hard to judge whether the Huoshan fault has ruptured through the Mianshan west fault and made the synchronous activity of the Taigu fault during the occurrence of 1303 Hongdong $M_{\mathrm{S}} 8.0$ earthquake (Xie et al. 2004). However, more moderate earthquakes $\left(M_{\mathrm{L}} \geq 3.0\right)$ were recorded at the south segment of the Taigu fault where the Taigu fault intersects with NW-SE striking faults at the south edge of Taiyuan basin (Fig. 2). In addition, at Site \#3 more complex magnetic fabrics are observed.

Compared with the focal mechanism data, AMS mainly reflects past directions of maximum compression and extension that has applied on the rocks (Tarling and Hrouda 1993). For instance, in a simple compressional case, magnetic lineation ( $K_{1}$ axes) is parallel to the folds axes in weakly deformed rocks (Borradaile and Tarling 1981; Hrouda 1982; Sagnotti et al. 1998), whereas in an extensional case, the orientation of the $K_{1}$ axes indicates the regional stretching direction perpendicular to the main normal faults or following the bedding dip (Mattei et al. 1997; Cifellia et al. 2005). As shown in the result section, the AMS data obtained at the three selected sites along the Taigu fault zone give similar distributions of $K_{1}$ orientation (Fig. 4), striking NW-SE direction with a good cluster of data points. Previous geological studies indicate an extensional regime, normal faulting with strike-slip component, of this region. It is therefore concluded that this region was mainly under the control of NW-SE stretching in the past. The rose diagram of $K_{1}$ axes is plotted in Fig. 5, exhibiting a similar result.

As mentioned in the result section, AMS axes of Site \#3 seem not grouped as well as sites \#1 and 2. Especially some data points of $K_{3}$ are observed distributing along the NNE-SSW orientation. This is probably caused by the relatively more complex local tectonic settings of Site \#3. As shown in Fig. 1, Site \#3 is located at the south segment of the Taigu fault, where the Taigu fault intersects with the 


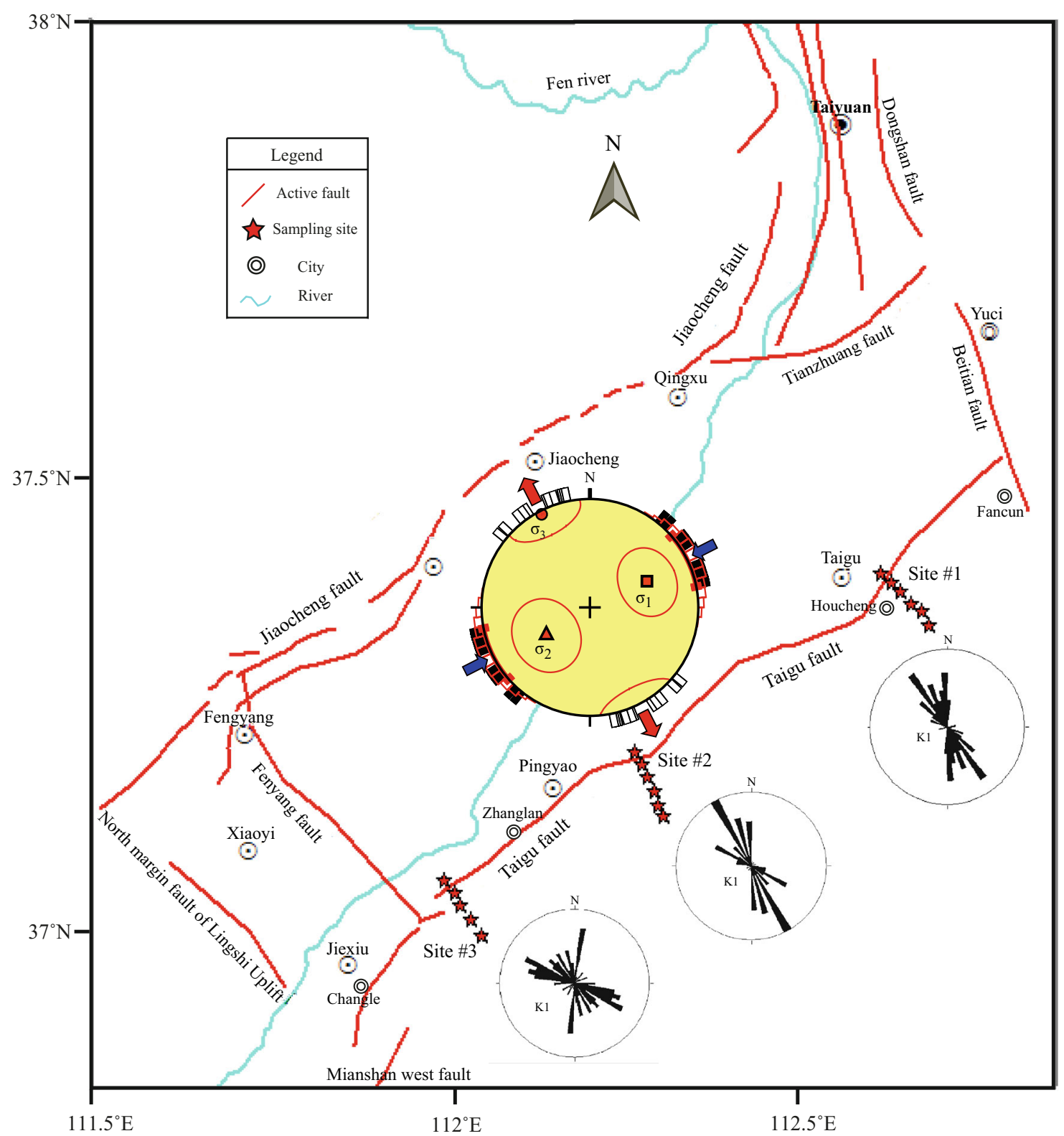

Fig. 5 Stress pattern and the rose diagrams of the maximum principal axis $\left(K_{1}\right)$ of three sites along the Taigu fault zone

NW-SE striking Fenyang fault and the north fault of Lingshi uplift. That may be the reason of that in this area the accumulated stress is higher than that in the surrounding areas, as indicated by the mapping of $b$-values (Yi et al. 2004). Additionally, the south segment is in connection with the Mianshan west fault (some geologists think it is the Huoshan fault which has ruptured through during the Hongdong $1303 M_{\mathrm{S}} 8.0$ earthquake, e.g., Xie et al. 2004), the local stress field at the Site \#3 might have been influenced by the neotectonic activities of the Huoshan fault.

Through the comparison of stress field between the present and the past, we find that the local stress field generally coincides to the orientation of the past stress field inferred from magnetic fabrics of sedimentary rocks in Neogene. This is easy to be understood why the Shanxi rift system has been extending continuously, and consistent with the geological evidence that shows the similar conclusion (Deng et al. 1973; Xu and Ma 1992; Zhang et al. 1998). However, the difference from the results inferred from focal mechanism data is observed that orientation of magnetic fabrics indicates the dominated normal faulting regime around the Taigu fault system, while the strike-slip component is hard to be seen (Fig. 4). We think that this difference is mainly resulted from the completely different datasets, reflecting different situations at different time periods. 
AMS of rocks might be influenced by other factors than tectonic deformations, e.g., unreformed rocks may exhibit a primary AMS acquired during the processes of rock formation. Identifying the primary magnetic fabric and isolating the magnetic fabric of tectonic origin from other origins are very important but at most time difficulty or impossible to be realized (Till et al. 2010). In this study, before the analysis of AMS we assumed that the primary magnetic fabric of all samples is isotropy, as many studies generally made. We can also observe some differences between the results from the SLICK and the TENSOR methods, e.g., the slight difference in orientations of the principal stresses $\sigma_{1}$ and $\sigma_{2}$. The stress field by the SLICK shows more of the normal faulting regime, whereas the result by the TENSOR gives more strike-slip components. However, such difference is acceptable as the two methods are completely independent, such as the different ways of determining nodal planes. Detailed comparisons of the two methods and corresponding explanations have been given in Delvaux and Barth (2010) and Li et al. (2015b).

As indicated by field surveys, the bedrock boundary between the mountain and basin along the Taigu fault is not as clear as that along the Jiaocheng fault (Xie et al. 2004). This might indicate that the active rate of the Taigu fault isnot high and without significant influence on the local stress field from outside tectonic events, e.g., the reactivity of the Huoshan fault, a relatively long time is needed to trigger an earthquake $M \geq 7.0$ along the Taigu fault zone. The fact that since the human recordings no strong earthquake of $M_{\mathrm{S}}>5.5$ was recorded also shows this situation. However, due to the intersecting of different faults at the south segment of the Taigu fault, the attention is still needed for the seismic risk in the future.

\section{Conclusions}

From this study based on our focal mechanism data set, stress inversion and analysis of magnetic fabrics along the Taigu fault zone, the following conclusions can be drawn:

(1) The present-day stress status of the area around the Taigu fault zone is characterized by a stable maximum NNW-SSE extension and a maximum ENE-WSW compressional stress, which feature is consistent with GPS data and geological surveys.

(2) The study on the magnetic fabrics of sedimentary rocks along the Taigu fault indicates that the orientations of principal stress axes from magnetic fabrics of sedimentary rocks in Neogene coincide to the orientations of principal stress axes from focal mechanisms.
(3) The south segment of the Taigu fault displays more activity of moderate earthquakes, more complicated magnetic fabrics and higher stress accumulation from the mapping of b-values ( $\mathrm{Yi}$ et al. 2004). It is connected with the Mianshan west fault and intersects with NW-SE striking Fenyang fault and with the north fault of the Lingshi uplift at the south edge of Taiyuan basin. This may be the area needing more attention in terms of seismic risk along the Taigu fault.

Acknowledgments We are grateful to the editor and the two reviewers for their constructive comments and suggestions, which helped to improve the manuscript significantly. We thank WeipingAn and Guirang Hu from Earthquake Administration of Shanxi Province for their help during the rock sampling in the field. This work is partly funded by Open Fund of State Key Laboratory of Earthquake Dynamics, CEA (LED2011B05), the Foundation for the Returned Overseas of Shanxi Province (121) and the National Science Fund of Shanxi Province (Youth, 2010021005).

Open Access This article is distributed under the terms of the Creative Commons Attribution 4.0 International License (http://crea tivecommons.org/licenses/by/4.0/), which permits unrestricted use, distribution, and reproduction in any medium, provided you give appropriate credit to the original author(s) and the source, provide a link to the Creative Commons license, and indicate if changes were made.

\section{References}

Borradaile GJ (1991) Correlation of strain with anisotropy of magnetic susceptibility (AMS). Pure Appl Geophys 135:15-29

Borradaile G, Alford C (1987) Relationship between magnetic susceptibility and strain in laboratory and experiments. Tectonophysics 133:121-135

Borradaile GJ, Alford C (1988) Experimental shear zones and magnetic fabrics. J Struct Geol 10(8):895-904

Borradaile GJ, Tarling DH (1981) The influence of deformation mechanisms on magnetic fabrics in weakly deformed rocks. Tectonophysics 77:151-168

Cifellia F, Matteia M, Chadimab M, Hirtc AM, Hansen A (2005) The origin of tectonic lineation in extensional basins: combinedneutron texture and magnetic analyses on "undeformed" clays. Earth Planet Sci Lett 235:62-78

Delvaux D, Sperner B (2003) Stress tensor inversion from fault kinematic indicators and focal mechanism data: the TENSOR program. In: New insights into structural interpretation and modelling, vol 212. Special Publication, Geological society, London, pp 75-100

Delvaux D, Barth A (2010) African stress pattern from formal inversion of focal mechanism data. Tectonophysics 482:105-128

Deng QD, Wang K, Wang Y, Tang H, Wu Y, Ding M (1973) On the tendency of seismicity and the geological set-up of the seismic belt of Shanxi graben. Sci Geol Sin 1:11

Dreger DS (2002) TDMT_INV: time-domain seismic moment tensor inversion. In: Lee WHK, Kanamori H, Jennings PC, Kisslinger C (eds) International handbook of earthquake and engineering seismology, Part B. Academic Press, Amsterdam, p 1627 (and files on attached CD-ROM) 
Ferré EC, Gébelin A, Till JL, Sassier C, Burmeister KC (2014) Deformation and magnetic fabrics in ductile shear zones: a review. Tectonophysics 629:179-188

Fleming EJ, Harold L, Stevenson CTE, Petronis MS, Benn DI, Hambrey MJ (2013) Magnetic fabrics in the basal ice of a surgetype glacier. J Geophys Res Earth Surf 118(4):2263-2278

Gébelin A, Martelet G, Chen Y, Brunel M, Faure M (2006) Structure of late Variscan Millevaches leucogranite massif in the French Massif Central: AMS and gravitymodeling results. J Struct Geol 28:148-169

Gentoso MJ, Evenson EB, Kodama KP, Iverson NR, Alley RB, Berti C, Kozlowski A (2012) Exploring till bed kinematics using AMS magnetic fabrics and pebble fabrics: the Weedsport drumlin field, New York State, USA. Boreas 41:31-41

Gephart JW, Forsyth DW (1984) An improved method for determining the regional stress tensor using earthquake focal mechanism data-application to the San-fernando earthquake sequence. J Geophys Res 89:9305-9320

Gorgun E, Bohnhoff M, Bulut F, Dresen G (2010) Seismotectonic setting of the Karadere-Duzce branch of the North Anatolian Fault Zone between the 1999 Izmit and Duzce ruptures from analysis of Izmit aftershock focal mechanisms. Tectonophysics 482:170-181

Graham JW (1954) Magnetic susoeptibility anisotropy, an unexploited petrofabric element. Bull Geol Soc Am 65:1257-1258

Guang CY, Sun GX (1993) Characteristics of earthquake activities of Taiyuan basin in history and estimation of the seismic situation in future. Earthq Res Shanxi 72(1):3-8 (in Chinese with English abstract)

Hardebeck JL, Hauksson E (2001) Crustal stress field in southern California and its implications for fault mechanics. J Geophys Res Solid Earth 106:21859-21882

He JK, Liu M, Li YX (2003) Is the Shanxi rift of northern China extending? Geophys Res Lett 30:4

Hrouda F (1982) Magnetic anisotropy of rocks and its application in geology and geophysics. Geophys Surv 5:37-82

Hrouda F (1993) Theoretical models of magnetic anisotropy to strain relationship revisited. Phys Earth Planet Inter 77:237-249

Jelinek V (1981) Characterization of the magnetic fabric of rocks. Tectonophysics 79:T63-T67

Kissel C, Barrier E, Laj C, Lee TQ (1986) Magnetic fabric in 'undeformed' marine clays from compressional zones. Tectonics 5:769-781

Li B, Havskov J, Ottemöller L, Sørensen MB (2015a) New magnitude scales, $M_{\mathrm{L}}$ and spectrum based $M_{\mathrm{w}}$ for the area around Shanxi Rift System, North China. J Seismol 19:141-158

Li B, Atakan K, Sørensen BM, Havskov J (2015b) Stress pattern of the Shanxi rift system, North China, inferred from the inversion of new focal mechanisms. Geophys J Int 201:505-527

Liu W, Zhao XP, An WP, Zhang KJ (1993) The results of the focal mechanism in Shanxi Province. Earthq Res Shanxi 2:7-12 (in Chinese with English abstract)

Liu M, Yang Y, Shen Z, Wang S, Wang M, Wan Y (2007) Active tectonics and intracontinental earthquakes in China: The kinematics and geo dynamics. In: Stein S, Mazzotti S (ed) Continental intraplate earthquakes: science, hazard, and policy issues. Geological society of America special paper 425, pp 299-318

Mamtani MA, Piazolo S, Greiling RO, Kontny A, Hrouda F (2011) Process of magnetitefabric development during granite deformation. Earth Planet Sci Lett 308(1-2):77-89

Mattei M, Sagnottib L, Faccennaa C, Funiciellob R (1997) Magnetic fabric of weakly deformed clay-rich sediments in the Italian peninsula: relationship with compressional and extensional tectonics. Tectonophysics 271:107-122
Michael AJ (1984) Determination of stress from slip data-faults and folds. J Geophys Res 89:1517-1526

Michael AJ (1987) Use of focal mechanisms to determine stress-a control study. J Geophys Res 92:357-368

Owens WH, Rutter EH (1978) The development of magnetic susceptibility anisotropy through crystallographic preferred orientation in a calcite rock. Phys Earth Planet Inter 16:215-222

Parés JM (2004) How deformed are weakly deformed mudrocks? Insights from magnetic anisotropy. Geological Society, London, Special Publications 238:191-203

Parés JM, Van der Pluijm BA (2002) Evaluating magnetic lineations (AMS) in deformed rocks. Tectonophysics 350:283-298

Parés JM, van der Pluijm BA, Dinares-Turell J (1999) Evolution of magnetic fabrics during inspicient deformation of mudrock (Pyrenees, northern Spain). Tectonophysics 307:1-14

Qu W, Lu Z, Zhang Q, Li ZH, Peng JB, Wang QL, Drummond J, Zhang M (2014) Kinematic model of crustal deformation of Fenwei basin, China based on GPS observations. J Geodyn $76: 1-8$

Rathore JS (1979) Magnetic susceptibility anisotropy in the Cambrian slate belt of NorthWales and correlation with strain. Tectonophysics 53:83-97

Reasenberg P, Oppenheimer D (1985) Fpfit, fpplot, and fppage: Fortran computer programs for calculating and displaying earthquake fault plane solutions. Technical report, U.S. Geol. Survey

Rochette P, Jackson MJ, Aubourg C (1992) Rock magnetism and the interpretation of anisotropy of magnetic susceptibility. Rev Geophys 30(3):209-226

Sagnotti L, Speranza F, Winkler A, Mattei M, Funicello R (1998) Magnetic fabric of claysediments from external northern Apennines (Italy). Phys Earth Planet Inter 105:73-93

Shen Z, Wan Y, Gan W, Li T, Zeng Y (2004) Crustal stress evolutionof the last 700 years in North China and earthquake sequence. Earthq Res China 20:211-228 (in Chinese with an English abstract)

Snoke JA (2003) FOCMEC: Focal mechanism determinations (chap. 85.12). In: Lee WHK, Kanamori H, Jennings PC, Kisslinger C (eds) International handbook of earthquake and engineering seismology. Academic Press, San Diego

Snoke JA, Munsey JW, Teague AG, Bollinger GA (1984) A program for focal mechanism determination by combined use of polarity and SV-P amplitude ratio data. Earthq Notes 55:15

Tarling DH, Hrouda F (1993) The magnetic anisotropy of rocks. Chapman and Hall, London, 217 pp

Till JL, Jackson MJ, Moskowitz BM (2010) Remanence stability and magnetic fabric development in synthetic shear zones deformed at $500^{\circ} \mathrm{C}$. Geochem Geophys Geosyst 11:Q12Z21. doi:10.1029/ 2010GC003320

Wan YG (2010) Contemporary tectonic stress field in China. Earthq Sci 23:377-386

Wang SJ, Yang JC (1996) Characteristics of neotectonic movement in Jinzhou Basin. In: Wang NL, Yang JC, Xia ZK (eds) Cenozoic sedimentation and tectonic geomorphology in the Shanxi Graben. Science Press, Beijing, pp 260-277 (in Chinese)

Xie XS, Jiang WL, Wang HZ, Feng XY (2004) Holocene activities of the Taigu fault zone, Shanxi Province, in relationship to the 1303 Hongdong $M=8$ earthquake. Acta Seismologica Sinica 26(3):281-293 (in Chinese with an English abstract)

Xie XS, Jiang WL, Sun CB, Yan CG, Feng XY (2008) Comparison study on Holocene paleoseismic activities among multi-tranches along tehJiaocheng fault zone, Shanxi. Seismol Geol 30(2):412-430 (in Chinese with an English abstract)

$\mathrm{Xu} \mathrm{XW} \mathrm{(1989)} \mathrm{The} \mathrm{characteristic} \mathrm{of} \mathrm{neotectonics} \mathrm{and} \mathrm{formation}$ mechanism of the Shanxi graben system [D]. Doctroal 
dissertation, Institute of Geology, China Earthquake Administration, Beijing, pp 73-75 (in Chinese)

Xu XW, Deng QD (1990) The features of late Quaternary activity of the peidmont fault of Mt. Huoshan, Shanxi province and 1303 Hongdong earthquake $\left(M_{\mathrm{S}}=8\right)$. Seismol Geol 12:21-30 (in Chinese with English abstract)

Xu XW, Ma XY (1992) Geodynamics of the Shanxi rift system, China. Tectonophysics 208:325-340

Xu ZH, Wang SY, Huang YR, Gao AJ (1992) Tectonic stress field of China inferred from a large number of small earthquakes. J Geophys Res 97(B8):11867-11877

Xu JR, Zhao ZX, Ishikawa Y (2008) Regional characteristics of crustal stress field and tectonic motions in and around Chinese Mainland. Chin J Geophys 51(3):770-781 (in Chinese with English abstract)
Yang CX (1996) A new understanding of the tectonic framework of Taiyuan basin and the level of seismic activity. J Geol Min Res North China 11(2):226-231 (in Chinese)

Yi GX, Wen XZ, Xu XW (2004) Average recurrence intervals of strong earthquakes and potential risky segments along the TaiguLinfen portion of the Shanxi graben system. Acta Seismologica Sinica 26(4):288-295 (in Chinese with an English abstract)

Zhang YQ, Mercier JL, Vergely P (1998) Extension in the graben systems around the Ordos (China), and its contribution to the extrusion tectonics of south China with respect to GobiMongolia. Tectonophysics 285:41-75

Zhao JQ, Gao SY, Bo JJ, Zhang DW (2005) A seismic fault which could cause earthquake larger than $M 7.0$ is found at an exploratory channel in Xizhang of Taiyuan, Shanxi. Earthq Res Shanxi 122(3):1-3 